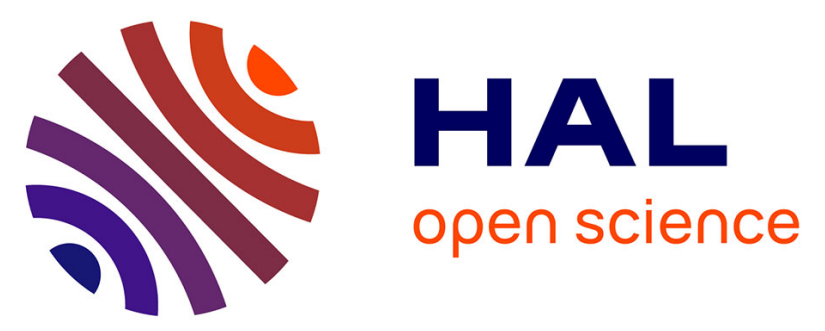

\title{
Impact of reducing fat, salt and sugar in commercial foods on consumer acceptability and willingness to pay in real tasting conditions: A home experiment
}

Sébastien Romagny, Emilie Ginon, Christian Salles

\section{- To cite this version:}

Sébastien Romagny, Emilie Ginon, Christian Salles. Impact of reducing fat, salt and sugar in commercial foods on consumer acceptability and willingness to pay in real tasting conditions: A home experiment. Food Quality and Preference, 2017, 56, Part A (Part A), pp.164-172. 10.1016/j.foodqual.2016.10.009 . hal-01430152

\section{HAL Id: hal-01430152 \\ https://u-bourgogne.hal.science/hal-01430152}

Submitted on 26 Sep 2017

HAL is a multi-disciplinary open access archive for the deposit and dissemination of scientific research documents, whether they are published or not. The documents may come from teaching and research institutions in France or abroad, or from public or private research centers.
L'archive ouverte pluridisciplinaire HAL, est destinée au dépôt et à la diffusion de documents scientifiques de niveau recherche, publiés ou non, émanant des établissements d'enseignement et de recherche français ou étrangers, des laboratoires publics ou privés.

\section{(1) $(1) \Theta$}

Distributed under a Creative Commons Attribution - NonCommercial - NoDerivatives 44.0 


\title{
Impact of reducing fat, salt and sugar in commercial foods on consumer acceptability and willingness to pay in real tasting conditions: A home experiment
}

\author{
Sébastien Romagny ${ }^{\mathrm{a}}$, Emilie Ginon ${ }^{\mathrm{b}}$, Christian Salles ${ }^{\mathrm{a}, *}$ \\ ${ }^{a}$ CSGA (Centre des Sciences du Goût et de l'Alimentation), CNRS, INRA, Université de Bourgogne Franche-Comté, F-21000 Dijon, France \\ ${ }^{\mathrm{b}}$ Université de Bourgogne Franche-Comté, ESC Dijon - CEREN, F-21000 Dijon, France
}

\section{A R T I C L E I N F O}

\section{Article history:}

Received 31 May 2016

Received in revised form 20 October 2016

Accepted 20 October 2016

Available online 22 October 2016

\section{Keywords:}

Home experiment

Ranking

Consumer behaviour

Sensory evaluation

Pleasantness

Willingness to pay

\begin{abstract}
A B S T R A C T
Decreasing obesity or cardiovascular disease can be achieved by eating healthier foods with reduced contents of fat, salt and sugar. However, these ingredients have a significant impact on the sensory quality of the food products that contain these ingredients, especially cooked sausage, chorizo, dry sausage, cheese and muffins. In this study, consumer appreciation of these five commercialized products (nonreformulated versions) and their respective reformulated versions with reduced contents of salt, fat and sugar was tested. An original home experiment was performed to assess consumer appreciation in natural consumption conditions. The experiment was divided into two steps that correspond to a pleasantness rating and a willingness to pay task. The two measurements were expected to yield comparable results with two aspects of consumer appreciation. Non-reformulated and reformulated versions were compared with a store brand and a trademark in a ranking task to evaluate their pleasantness positioning on the market. This latter experiment, which was conducted in a laboratory, enabled the validation of the home experiment. The results indicated that the cooked sausage reformulation did not maintain consumer appreciation and reduced its positioning on the market. For cheese and muffins, the reformulation did not affect the product pleasantness. The reformulation of dry sausage and chorizo not only maintained consumer appreciation but also increased pleasantness, which was consistent with a higher reservation price of approximately $12 \%$ compared to the other samples. For most products in this experiment, new technologies contributed to significant reduction in fat, salt or sugar whilst maintaining consumer appreciation.
\end{abstract}

(c) 2016 Elsevier Ltd. All rights reserved.

\section{Introduction}

To satisfy the expectations of European Nutrition claims, agrifood companies have to decrease the amount of salt, fat and sugar in $30 \%$ of their products. However, these ingredients are known to contribute to consumer appreciation; therefore, changing the formulation process may endanger the sensory quality of these products (Brauss, Linforth, Cayeux, Harvey, \& Taylor, 1999; Drewnowski \& Greenwood, 1983; Drewnowski, Nordensten, \& Dwyer, 1998; Goh et al., 2011; Zoulias, Oreopoulou, \& Kounalaki, 2002). A major challenge is to maintain consumer appreciation and consumption while offering healthier food products for the consumer. Overcoming this challenge was the main goal of the FP7 European project TeRiFiQ (289397), which provides the results presented in this paper. As a starting point, food rich in fat, salt and sugar were

\footnotetext{
* Corresponding author.

E-mail address: christian.salles@inra.fr (C. Salles).
}

selected (such as cooked sausage, chorizo, muffin, dry sausage, and cheese; see EFSA (2008), European Commission. (2007), European Parliament. (2006). Then, different reduction strategies, such as modification of the industrial process (Desmond, 2006; Emorine, Septier, Thomas-Danguin, \& Salles, 2013), changes to the physicochemical and rheological properties of matrices (Mosca, Andriot, Guichard, \& Salles, 2015; Safa, Gatellier, Lebert, Picgirard, \& Mirade, 2015), the use of emulsions (Chapeau, Silva, Schuck, Thierry, \& Floury, 2016; Lobato-Calleros et al., 2008; Oppermann, Renssen, Schuch, Stieger, \& Scholten, 2015; PerezMoral, Watt, \& Wilde, 2014), the use of replacers (Katsiari, Voutsinas, Alichanidis, \& Roussis, 1997; Kloss, Meyer, Graeve, \& Vetter, 2015) or the addition of aromas (Lawrence, Salles, Septier, Busch, \& Thomas-Danguin, 2009; Syarifuddin, Septier, Salles, \& Thomas-Danguin, 2016), were applied. These technologies constitute valuable solutions for helping professionals who wish to reduce salt, sugar and fat contents; however, sensory studies are required to investigate consumer acceptability. As a final part of 
the project, this study evaluated 1 ) if reformulation maintained the sensory quality of the products and consumer acceptability considering pleasantness and willingness to pay and 2) if the reformulated products maintained their competitiveness according to other products on the market. To address the first objective, the commercialized non-reformulated versions (NR) of the products were compared with the non-commercialized reformulated versions $(\mathbf{R})$ of the products. For the second objective, "NR" and "R" versions were compared with other brands (a trademark and a store brand).

The challenge of this study was to assess the perception of the products in the most natural consumption conditions. As soon as "the most expensive but most realistic situation is when consumers take the product home and try it under normal circumstances on several occasions" (Lawless \& Heymann, 2010), the strategy was to set up a home experiment. Thus, participants had to taste separately the "NR" and "R" versions at home. Instead of other homeexperiments (e.g. HUT), very few questions were asked 1/ to maintain the most natural situation and $2 /$ to prevent the consumer to focus on the sensory characteristic of the samples that may endanger the following experiments. The paradigm of this home experiment required two steps. In the first step, a consumer had to taste the product and evaluate its pleasantness. Pleasantness measurements are usually performed to determine how intrinsic and extrinsic characteristics interact in the global perception and assess total product quality (Lange, Martin, Chabanet, Combris, \& Issanchou, 2002; Schifferstein, Kole, \& Mojet, 1999; Siret \& Issanchou, 2000). In the second step, a willingness to pay procedure was adapted to assess product valuation and product acceptability. Incentive measurements, such as auctions and the BeckerDeGroot-Marschak (BDM) mechanism (Becker, Degroot, \& Marschak, 1964), are employed to reveal consumer willingness to pay. Willingness to pay experiments present subjects with real purchase decisions and enable them to reveal their true preferences and values for different goods (Ginon, Combris, Loheac, Enderli, \& Issanchou, 2014; Ginon, Lohéac, Martin, Combris, \& Issanchou, 2009; Lange et al., 2002; Noussair, Robin, \& Ruffieux, 2004a,2004b; Vickrey, 1961).

To assess the second objective, which was to evaluate whether reformulated foods maintain their competitiveness on the market, a direct comparison of the versions was performed using a rank test. For each type of food product, consumers had to rate the pleasantness of "NR", "R", a store brand and a trademark. The experiment was conducted in a laboratory, without packaging and in the controlled conditions of sensory rooms. Ranking tasks enable the direct comparison of samples and is appropriate for comparing the pleasantness of products in the same perceptual space (SSHA, 1998). Therefore, this experiment was performed to cross-validate the results of the experiment that was conducted at home regarding the position of the "NR" version $v s$ the "R" version and assess the pleasantness positioning of these two versions compared with other brands on the market.

The great originality of this paper belong first to the different methods used to assess the product appreciation. The experimental design enables cross validating home and classic tasting conditions in lab with very similar product versions (reformulated vs non-reformulated). At home, the one-shot evaluation of pleasantness and willingness to pay is supposed to reflect real tasting situation leading, or not, to a subsequent purchase. This paradigm is particularly relevant at the final stage of product developments to assess whether a new formulation maintains their appreciation and valorisation. This is the case of the present study where the reformulated products are expected to be ready for commercialization. Inexpensive food products were delivered in shopping-bags to contextualise the experiment and enrolled participants in the most ecological conditions. This provides another originality of the present work since experimental economics studies conducted at home and involving inexpensive food products are underrepresented in the literature.

\section{Materials and methods}

The study was divided into two experiments. Experiment 1 was conducted at home, where two measurements were performed to reveal consumer acceptability: pleasantness rating and willingness to pay mechanism. The objective of the experiment was to evaluate "NR" and "R" versions in real consumption conditions. Experiment 2 corresponded to a ranking task in a laboratory setting and evaluates these products positioning compared to other brands of the market.

\subsection{Participants}

Participants were randomly selected from a panel of volunteer consumers (ChemoSens Platform's PanelSens database ${ }^{1}$ ). A total of 144 subjects, who are described in Table 1, were recruited from the vicinity of Dijon (France) for Experiment 1 (at home). A total of 135 subjects of Experiment 1 also agreed to participate in Experiment 2 (in a laboratory). Consumers were selected only if they significantly participated in purchasing food products for their use or for their family. They declared to have no aversion to pork products, cooked sausage, and cheese or baked goods and self-reported no problems with their sense of smell or allergies. They were asked for their consumption frequencies regarding these products and the variable was considered in models. Even if the participants significantly eat more frequently dried sausage and cheese than the other products, consumption frequency did not explain the results. The selected participants signed an informed consent form at the beginning of the study; the objective of the experiment was not revealed at this time. The subjects received a fee of $20 €$ (Experiment 1 ) or $30 €$ (Experiments $1 \& 2$ ). The experiments were performed in accordance with the Declaration of Helsinki for Medical Research Involving Human Subjects and ethical rules enforced by French law; the protocol has been viewed and approved by the human research ethics committee (Comité de Protection des Personnes Est-1, No. 2013/64 - IDRCB 2013 - A01084-41 on 11/21/2013 and Agence Nationale de la Santé et du Médicament, No. B 131283-81 on $11 / 20 / 2013)$.

\subsection{Food samples}

For Experiment 1, five food product types were obtained from the European industrial partners of the TeRiFiQ project. They consisted of mini dry sausages (Boadas), cooked sausage (Leiv Vidar), soft chorizo (Boadas), "Trappist" semi hard cheese (Orval) and muffins (Millba). For each food products, two versions were compared: a non-reformulated version (NR), which was already commercialized, and a reformulated version $(\mathbf{R})$, which was reduced in salt $(\mathrm{NaCl})$, fat or sugar and not commercialized (for details of the reduction, refer to Table 2 ). The two versions were strictly identical in terms of shape, colour and weight. The reductions strategies used were more or less specific of each product. To prevent the effect of packaging on consumer beliefs and to ensure natural conditions, both versions were packed in the commercialized packaging of the NR version (Table 2). Therefore, the participants had no external cues to discriminate between the two versions of the samples and were confident in their ability to taste an ordinary industrial food that they may find on the market. Both versions provided the same, and worst, legal nutritional information. In

\footnotetext{
${ }^{1}$ Declared to the Commission National Informatique et Libertés (\#1148039).
} 
Table 1

Socio-demographic characteristics of participants $(n=144)$.

\begin{tabular}{|c|c|}
\hline & $\%$ of participants \\
\hline \multicolumn{2}{|l|}{ Gender } \\
\hline Female & 58 \\
\hline Male & 42 \\
\hline \multicolumn{2}{|l|}{ Age (years) } \\
\hline 20-35 $($ Average $=25.6)$ & 47 \\
\hline $36-50($ Average $=43.9)$ & 53 \\
\hline $51-70($ Average $=59.3)$ & 44 \\
\hline \multicolumn{2}{|c|}{ Number of adults in the household } \\
\hline 1 & 27 \\
\hline 2 & 35 \\
\hline 3 & 13 \\
\hline 4 & 21 \\
\hline 5 & 4 \\
\hline \multicolumn{2}{|c|}{ Number of children (<18 y.o.) living at home } \\
\hline 0 & 73 \\
\hline 1 & 11 \\
\hline 2 & 15 \\
\hline 3 & 1 \\
\hline \multicolumn{2}{|l|}{ Professional situation } \\
\hline Full-time position & 64 \\
\hline Student & 14 \\
\hline Retired & 17 \\
\hline Looking for job & 5 \\
\hline \multicolumn{2}{|l|}{ Education } \\
\hline No study certificate & 17 \\
\hline Secondary school & 15 \\
\hline High school & 36 \\
\hline Bachelor & 16 \\
\hline Master and higher & 16 \\
\hline \multicolumn{2}{|l|}{ Net Salary of the household } \\
\hline $392-1000 €$ & 12 \\
\hline $1001-2000 €$ & 22 \\
\hline $2001-3000 €$ & 30 \\
\hline $3001-4000 €$ & 22 \\
\hline$>4001 €$ & 14 \\
\hline \multicolumn{2}{|l|}{ Financial situation } \\
\hline Financially comfortable & 8 \\
\hline It's ok & 40 \\
\hline It's just, I have to be careful & 39 \\
\hline It is very difficult & 10 \\
\hline Too difficult and I have debts & 3 \\
\hline
\end{tabular}

these conditions, the product ratings are suspected to be primarily based on flavour.

For Experiment 2, the previously described "R" and "NR" versions were employed. Both versions competed with one trademark and one store brand product from the French market. Consequently, participant had to sort a total of four samples per product type. The samples were presented without packaging.

\subsection{Experiment 1: Home experiment}

\subsubsection{General design}

Each participant received two shopping-bags that were separated by two weeks and was instructed to take them home. All instructions were given to the participants when they arrived to pick up their shopping-bag. A shopping-bag contained five product types with five answer forms that corresponded to each product. A shopping-bag contained a single version of each products; that is, all the reformulated products were in a same shopping-bag while all the NR products were in another. The order of shopping-bag presentation (NR vs R) was balanced among the participants and had no effect on the observed results $(p>0.3)$. The consumers had two weeks to taste the products in the most usual and natural conditions at home. They were instructed that they were "free to eat the sample in the manner that they chose when they wanted to eat, alone or with their family as they were accustomed to do every day (the entire shopping-bag has not necessary to be eaten

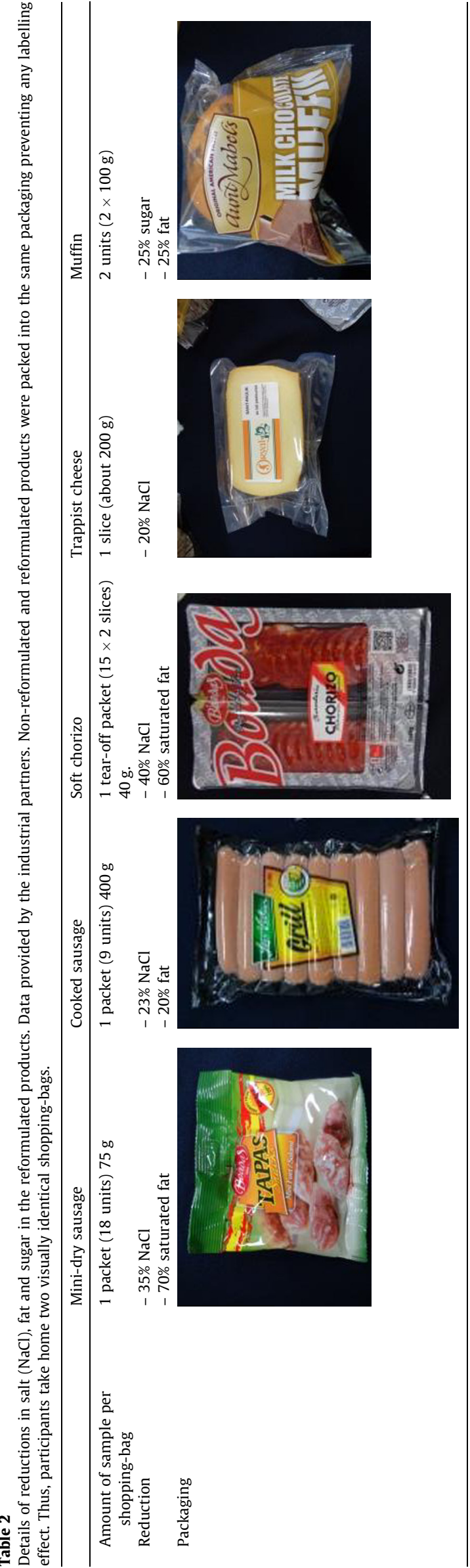


during a same meal)". They were instructed to use the appropriate answer forms when they ate a product and respond to each question. The answer forms contained two evaluations: a pleasantness rating and a willingness to pay assessment.

\subsubsection{Pleasantness rating}

During tasting, the participants had to evaluate the pleasantness of the product; this topic comprised the first question displayed by the answer form. They could respond to the question "Indicate how do you like this product" by using a $14 \mathrm{~cm}$ open and unstructured linear scale ranging from "I don't like it at all" to "I like it very much" as recommended by AFNOR (2012) and SSHA (1998). For the French participants, the word "liking" makes more sense but is interchangeable with pleasantness. Furthermore, the experimental design cannot enable the segregation between "liking" and "wanting" hence the use of the generic term "pleasantness" instead of "liking". The results of the pleasantness evaluation were converted to scores that ranged from 0 to 10 .

\subsubsection{Willingness to pay (WTP)}

The answer form displayed the WTP assessment consisting in a classical BDM mechanism adapted here for a home experiment (Noussair et al., 2004b; Ginon et al., 2014). Prior to the experiment, the principle of the BDM mechanism was explained to the participants using a example (Ginon et al., 2009). Instructions were provided on a paper that was added to the shopping-bags. This short note explained that the participants would submit a reservation price, that is, the participants indicated their reservation price on a "buying form", which represented the maximum price that they were willing to pay. The instruction was "Indicate on the box below the maximum price you are willing to pay to obtain this article". They could indicate either the unitary price or the price by kilo according to their purchasing habits. To maximize their involvement, the participants were informed that one product was sold at the end of the experiment. At the end of experiment 1, each participant randomly selected one product from the total of products tested to determine which product will be sold. For the selected product, the selling price was randomly chosen among a distribution of market prices that were adapted for each product. The selling price was compared with the reservation prices given by the participants. If the reservation price given by a consumer was higher than the final price, the consumers had to buy it at the final price. Otherwise, the product was not sold.

The distribution of the prices ranged from the lowest price observed on the market to the highest price observed on the market (Noussair et al., 2004b). These observed prices originated from a survey of eight shops and supermarkets in Dijon based on the 189 sampled prices. Is indicated hereafter the size of the sampling $(\mathrm{N})$ for each product and their price in $€ /$ kilo in

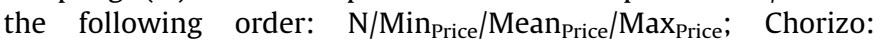
45/4.49/16.82/29.29; Dry-sausage: 51/9.27/16.91/28.67; Cookedsausage: 57/2.66/6.79/17.27; Cheese: 15/5.48/7.47/12.7; Muffin: $21 / 4.5 / 9.34 / 25.75$.

\subsection{Experiment 2: Ranking task in a laboratory}

For the five products, the previous versions ( $R$ and NR) were compared with a trademark and a store brand to evaluate the appreciation of the food samples in more controlled conditions and to compare the pleasantness of these versions with other brands on the market. Thus, Experiment 2 was conducted in an air conditioned and odourless room $\left(21 \pm 1^{\circ} \mathrm{C}\right)$ that was specifically designed for human sensory studies. Each participant received $12 \mathrm{~g}$ samples of each product for each version ( $R$, NR, store brand and trademark). Each sample was contained in a three-digitcoded plastic vial that enabled real blind conditions. Participants were instructed to sort the four samples of each product from the least appreciated to the most appreciated and to validate their ranking using a computer screen (Fizz software, Couternon, France). The order of the tasting of each sample (i.e. within a product type) was balanced among the participants and followed a Latin square experimental design. The products presentation order was similar among participants to realistically mimic a "meal": dry sausage, cooked sausage, chorizo, cheese and muffin. A two-minute delay between each product was imposed during which a participant had to rinse their mouth with mineral water. After tasting the chorizo, participants had to complete a questionnaire (seven minutes) while rinsing their mouth with water and a cracker to prevent the release of chorizo aroma in subsequent products.

\subsection{Statistical analyses}

All statistical analyses were conducted using R software (R Core Team, 2015). The pleasantness ratings and WTP data were subjected to an analysis of variance (ANOVA) using linear mixedeffect models with the participants as the random factor (nlme package, Pinheiro, Bates, DebRoy, Sarkar, \& R Core Team., 2015). Individual effects were initially added to the model but subsequently deleted if not significant. Pearson's correlation tests were performed to assess the link between pleasantness and WTP. The results of the sorting task were analysed with a linear model based on the ranks followed when significant by a pairwise post hoc test for multiple comparisons of mean rank sums, including a correction (Friedman-Nemenyi tests).

\section{Results and partial discussions}

\subsection{Participants}

Table 1 lists the socio-demographic characteristics of the 144 consumers who participated in the study. The effect of age on chorizo and muffin appreciation was measured $(\mathrm{p}<0.001)$ but without interaction with product version, which suggests a general tendency of younger participants to enjoy these products more than elderly participants $(\mathrm{r}=-0.18, \mathrm{p}=0.002)$. Younger participants were willing to pay a higher price for the muffins ( $p=0.009$ ), especially young women (age*sex, $\mathrm{p}=0.02$ ), regardless of the product version. Monthly incomes were converted to monthly incomes by persons in a household; in this case, participants with higher incomes were willing to pay a higher price for cheese and cooked sausages regardless of the version $(p=0.01)$. These marginal effects do not affect the conclusions of the paper.

\subsection{Experiment 1: Home evaluation of food products}

\subsubsection{Impact of reformulation of the food products on acceptance by consumers}

At home, the subjects were asked to rate pleasantness. Then, they were asked to consider a reservation price (WTP procedure). The results are detailed in Table 3 and illustrated in Figs. 1-5 (Panels A and B). For all products, the pleasantness scores were consistent with the reservation prices given by the participants as suggested by the significant correlations between WTP and appreciation ( $p<0.0001$, Table 3 ). For cooked sausage, the subjects considered the reformulated version $(\mathrm{R})$ to be less pleasant, and the reservation price did not significantly differ from the reservation price for the non-reformulated version. In this case, the reduction of fat and salt did not maintain consumer appreciation. Nevertheless, the participants did not change their valuation of this product. For Trappist semi-hard cheese and muffins, the participants similarly enjoyed the two versions ( $\mathrm{R}$ and NR) and they are willing to 
Table 3

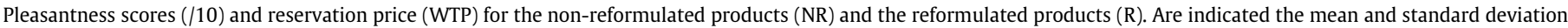
(sd) for these two variables as well as the results of mixed models with p-values. Correlations between pleasantness and WTP are informed in the last column.

\begin{tabular}{|c|c|c|c|c|c|c|c|c|c|c|c|}
\hline & \multicolumn{5}{|c|}{ Pleasantness $(/ 10)$} & \multicolumn{5}{|c|}{ WTP (in $€$ ) } & \multirow[t]{3}{*}{ Correlation } \\
\hline & \multicolumn{2}{|l|}{ NR } & \multicolumn{2}{|l|}{$\mathrm{R}$} & \multirow[b]{2}{*}{ Stats and Conclusion } & \multicolumn{2}{|l|}{ NR } & \multicolumn{2}{|l|}{$\mathrm{R}$} & \multirow[b]{2}{*}{ Stats and Conclusion } & \\
\hline & Mean & sd & Mean & sd & & Mean & sd & Mean & sd & & \\
\hline Cooked sausages & 4.08 & 2.5 & 3.56 & 2.3 & $\begin{array}{l}F(1137)=6.70, p=0.01 \\
\mathbf{N R}>\mathbf{R}\end{array}$ & 1.85 & 0.96 & 1.99 & 0.99 & $\begin{array}{l}F(1137)=3.28, p=0.073 \\
\mathbf{N R}=\mathbf{R}\end{array}$ & $\begin{array}{l}0.34 \\
\mathrm{p}<0.0001\end{array}$ \\
\hline Cheese & 5.44 & 2.32 & 5.47 & 2.07 & $\begin{array}{l}\mathrm{F}(1136)=0.036, \mathrm{p}=0.85 \\
\mathbf{N R}=\mathbf{R}\end{array}$ & 1.91 & 0.77 & 1.95 & 0.70 & $\begin{array}{l}F(1136)=0.55, p=0.46 \\
\mathbf{N R}=\mathbf{R}\end{array}$ & $\begin{array}{l}0.37 \\
p<0.0001\end{array}$ \\
\hline Muffin & 6.69 & 2.31 & 6.7 & 2.26 & $\begin{array}{l}F(1135)=0.08, p=0.78 \\
\mathbf{N R}=\mathbf{R}\end{array}$ & 1.10 & 0.52 & 1.13 & 0.55 & $\begin{array}{l}F(1138)=0.23, p=0.63 \\
\mathbf{N R}=\mathbf{R}\end{array}$ & $\begin{array}{l}0.33 \\
\mathrm{p}<0.0001\end{array}$ \\
\hline Dry-fermented sausage & 4.77 & 2.75 & 5.35 & 2.16 & $\begin{array}{l}\mathrm{F}(1137)=5.76, \mathrm{p}=0.017 \\
\mathbf{N R}<\mathbf{R}\end{array}$ & 1.11 & 0.58 & 1.27 & 0.51 & $\begin{array}{l}\mathrm{F}(1138)=8.33, \mathrm{p}=0.0045 \\
\mathbf{N R}<\mathbf{R}\end{array}$ & $\begin{array}{l}0.42 \\
p<0.0001\end{array}$ \\
\hline Chorizo & 4.47 & 2.31 & 5.24 & 2.38 & $\begin{array}{l}\mathrm{F}(1135)=13.72, \mathrm{p}<0.001 \\
\mathbf{N R}<\mathbf{R}\end{array}$ & 1.29 & 0.61 & 1.47 & 0.55 & $\begin{array}{l}\mathrm{F}(1136)=8.94, \mathrm{p}=0.003 \\
\mathbf{N R}<\mathbf{R}\end{array}$ & $\begin{array}{l}0.34 \\
p<0.0001\end{array}$ \\
\hline
\end{tabular}
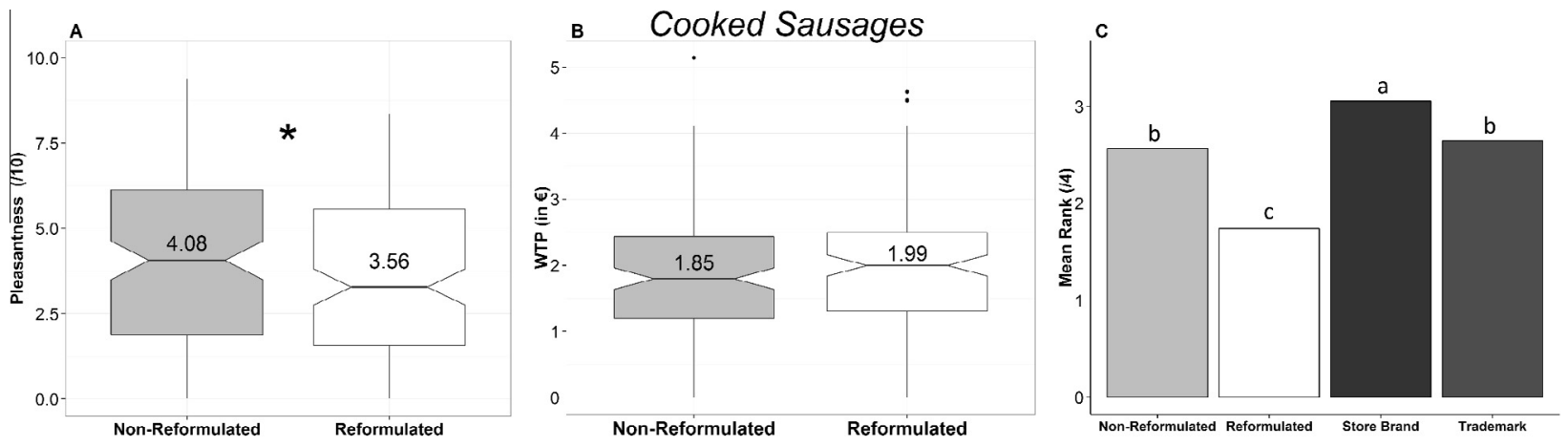

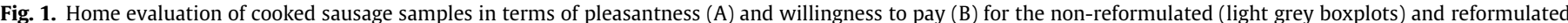

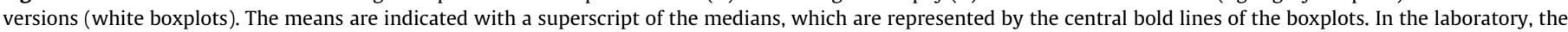

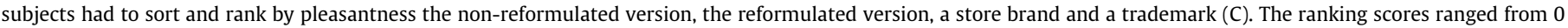
(less preferred) to 4 (preferred). Significant differences are indicated by the stars or letters that are superscripted $(p<0.05)$.
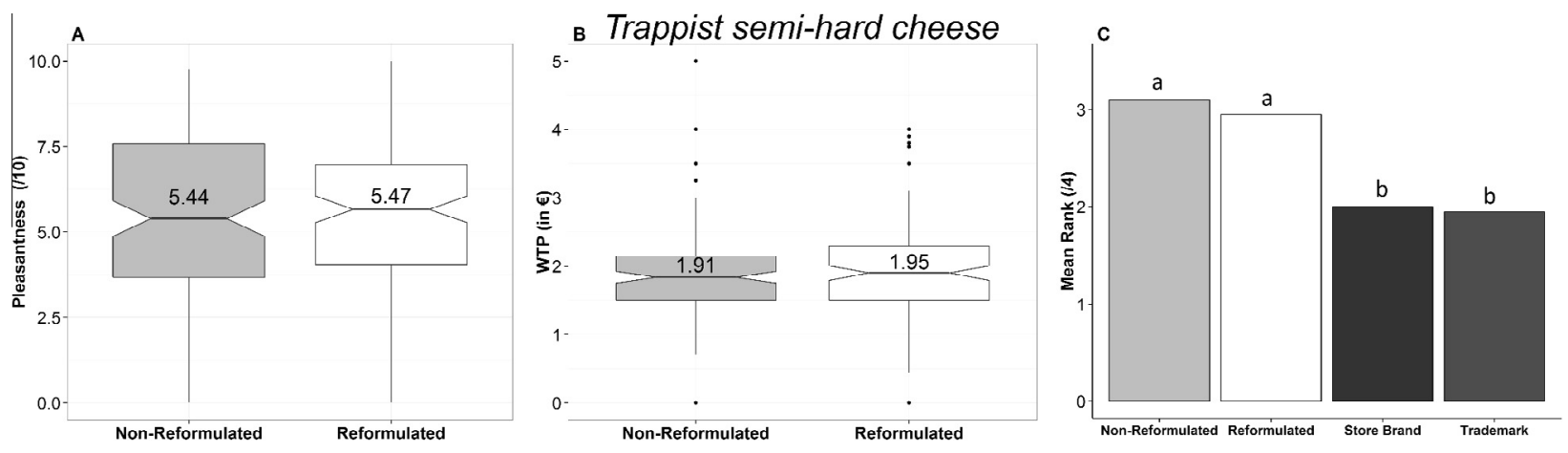

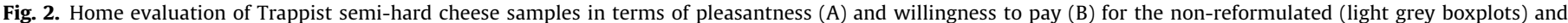

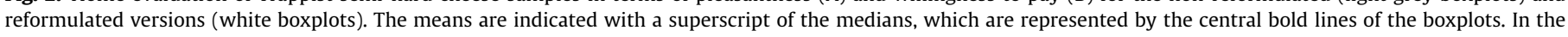

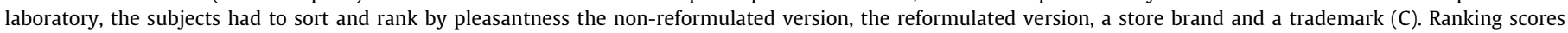
ranged from 0 (less preferred) to 4 (preferred). Significant differences are indicated by the stars or letters that are superscripted ( $p<0.05$ ).

pay similar prices. Thus, the objective was achieved as reformulation maintained consumer acceptability. Regarding dry-sausage and chorizo, the participants preferred the " $R$ " version and were willing to pay a higher price for this new reformulation process. These results surpassed expectations as reformulation not only maintained consumer acceptance but also improved the sensory quality of the products and consumer acceptability.

\subsection{Experiment 2: Ranking task in a laboratory}

For this task, the subjects had to sort and rank by pleasantness four coded samples of each product referring respectively to the
"NR" version, the "R" version, a store brand and a trademark. The products that ranked 1 st, 2 nd, 3rd and 4 th were allocated by 4 points, 3 points, 2 points and 1 point, respectively, which were employed to calculate the mean rank scores. Thus, the higher is the score, the greater is the pleasantness of the sample.

\subsubsection{Cooked sausages}

The rankings significantly differed among the cooked sausage samples, which suggests that some foods are preferred over other foods $(F(3)=39.5, \mathrm{p}<0.001)$. The "NR" version obtained a higher ranking (2.6/4); thus, it was preferred over the "R" version $(1.7 / 4$, $\mathrm{p}<0.001)$. The "R" version obtained the lowest score of all samples 

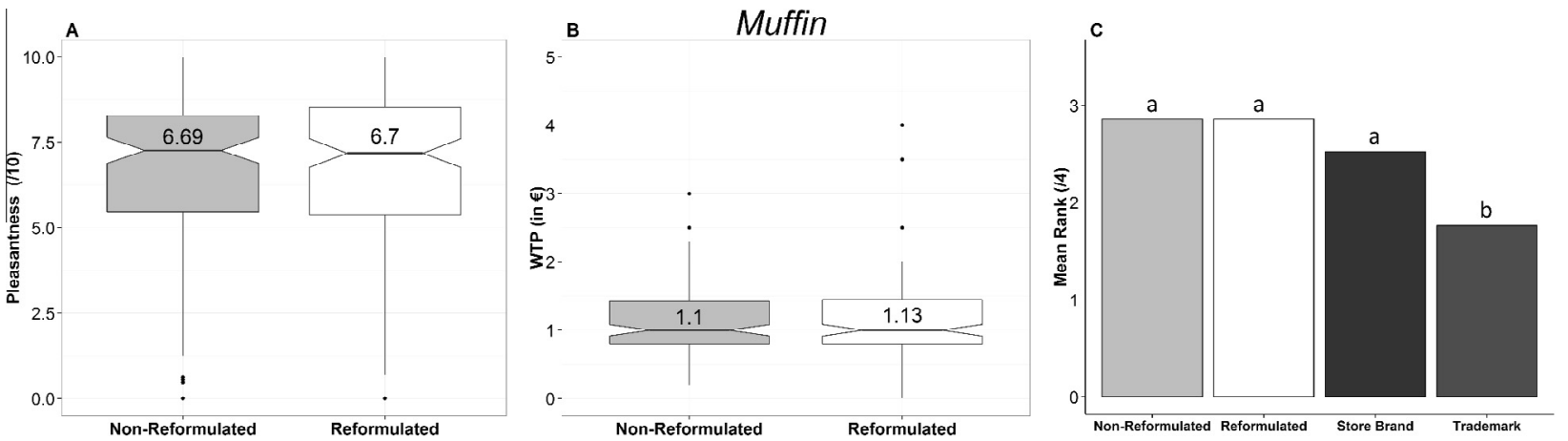

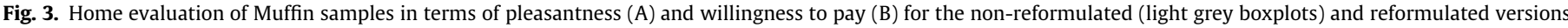

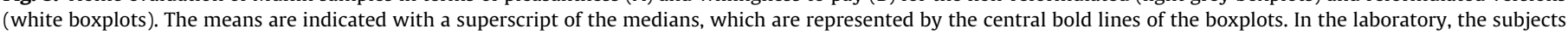

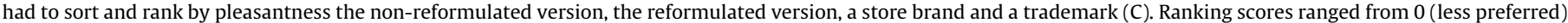
to 4 (preferred). Significant differences are indicated by the stars or letters that are superscripted $(p<0.05)$.
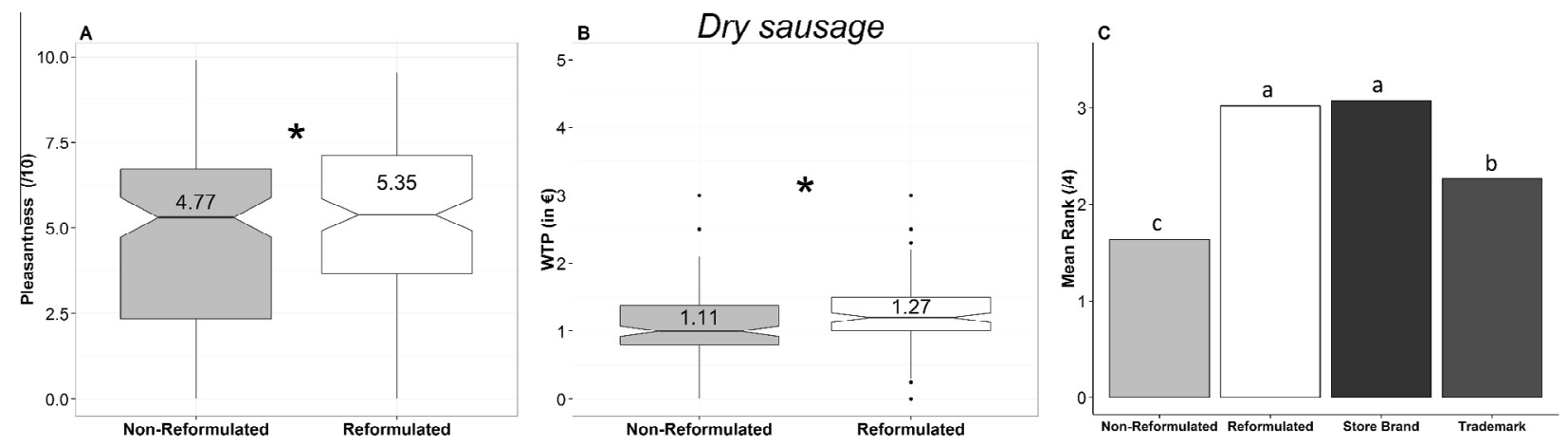

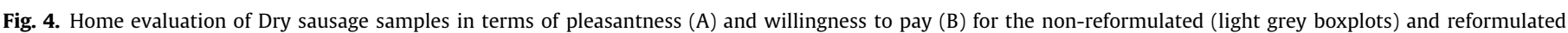

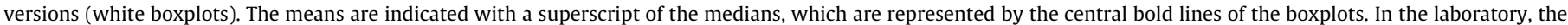

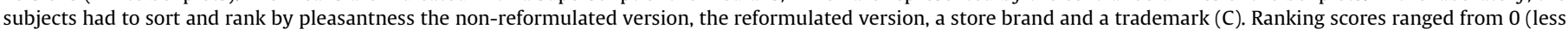
preferred) to 4 (preferred). Significant differences are indicated by the stars or letters that are superscripted $(p<0.05)$.
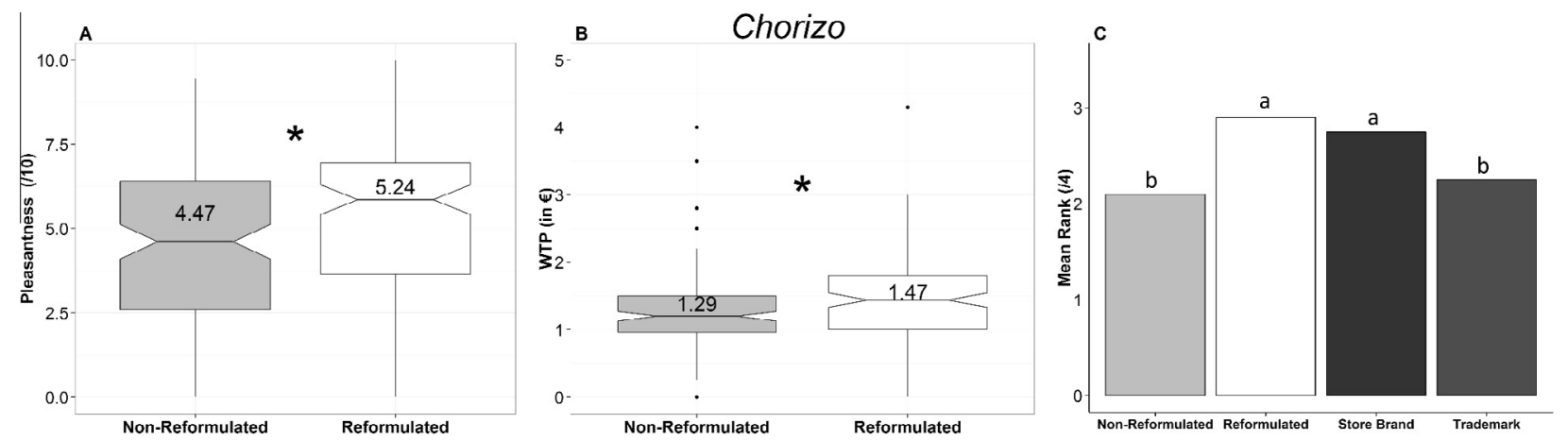

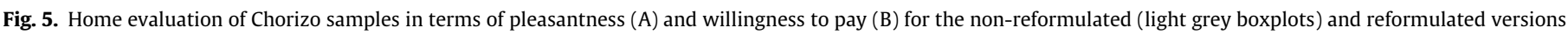

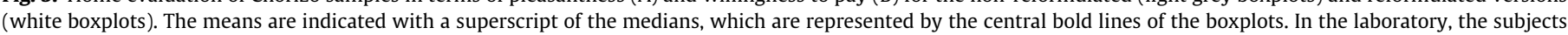

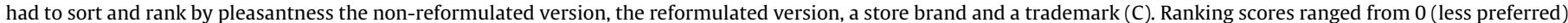
to 4 (preferred). Significant differences are indicated by the stars or letters that are superscripted $(p<0.05)$.

$(>2.6 / 4, \mathrm{p}<0.001)$, whereas the "NR" version did not initially differ from the trademark $(2.6 / 4, \mathrm{p}=0.96)$ in terms of preferences but was less preferred than the store brand (3.1/4, $\mathrm{p}=0.01$, Fig. 1C). The store brand was considered to be the most appreciated brand among the samples $(\mathrm{p}<0.047)$. Reformulation did not maintain consumer appreciation and devaluated the product compared with other brands of the market.

\subsubsection{Trappist semi-hard cheese}

The ranking of the cheeses differed among the samples $(F(3)$ $=51.6, \mathrm{p}<0.001)$. The "NR" version $(3.1 / 4)$ and the "R" version (2.9/4) obtained a high ranking score and their differences were not significant $(\mathrm{p}=0.76)$, which indicated that the pleasantness of these two versions cannot be distinguished. However, these samples obtained a better ranking score than the trademark and the store brand $(<2 / 4, p<0.001)$, which do not significantly differ ( $p=0.99$, Fig. 2C). For cheese, reformulation maintained consumer appreciation and enabled the product to maintain a good position compared with other brands.

\subsubsection{Muffin}

Similar results were obtained for muffins since the ranking differed significantly among samples $(F(3)=34.1, \mathrm{p}<0.001)$. The "NR" version obtained a high ranking score (2.9/4), which did not 
significantly differ from the " $R$ " version score $(2.9 / 4, p>0.99)$. The scores were higher than the scores for the trademark $(1.8 / 4$, $\mathrm{p}<0.001)$, which was the least pleasant sample $(\mathrm{p}<0.001)$. However, the scores for the two NR and R samples did not differ from the scores for the store brand (2.5/4, $\mathrm{p}=0.15$, Fig. $3 \mathrm{C})$. Reformulation maintained consumer appreciation and the product's position on the market.

\subsubsection{Dry sausage}

For dry sausage, the pleasantness ranking of the four samples significantly differed $(F(3)=69.6, \mathrm{p}<0.001)$. The reformulated product obtained a higher ranking score (3/4) than the score of the non-reformulated version (1.6/4), which indicated that it was preferred ( $p<0.001$ ). Note that the "NR" version, which was less preferred than the trademark $(2.3 / 4, \mathrm{p}<0.001)$ became preferred for its reformulated version $(3 / 4, \mathrm{p}<0.001)$. The store brand (ranking score 3.1/4) is a serious competitor of the " $R$ " version as both products were not discriminated in terms of pleasantness $(p=0.99$, Fig. 4C). For dry sausage, reformulation not only increased consumer appreciation but also enabled the product to surpass the trademark although it was initially less preferred.

\subsubsection{Chorizo}

Among the chorizo samples, a significant difference in pleasantness ranking was observed $(F(3)=17.6, \mathrm{p}<0.001)$. A significant difference was observed between the ranking scores of the "NR" version (2.1/4) and the "R" version (2.9/4) in favour of the reformulated sample $(\mathrm{p}<0.001)$. The "NR" version, which did not differ from the trademark $(2.3 / 4, \mathrm{p}=0.75)$ and was less appreciated than the store brand $(2.7 / 4, \mathrm{p}<0.001)$, became more appreciated than the trademark for its reformulated version $(p<0.001)$ and did not differ from the store brand ( $p=0.75$, Fig. $5 \mathrm{C})$. Reformulation increased consumer appreciation and enabled the product to become a serious competitor on the market although it was initially surpassed by the other brands.

\section{Discussion}

Based on food products that are known to contain high fat, salt and sugar contents, European SMEs and research centres partners in the TeRiFiQ project achieved the goal of developing new technologies to achieve a significant reduction of these unhealthy ingredients (e.g. Emorine et al., 2013; Perez-Moral et al., 2014; Mosca et al., 2015; Oppermann et al., 2015; Safa et al., 2015; Chapeau et al., 2016; Syarifuddin et al., 2016). Even if these technologies ensured product safety, stability and other aspects, consumer appreciation was not considered. At the end of the demonstration step of the project and after the reformulated food products were shown to be developed on an industrial scale, this study evaluated 1 ) if reformulation maintained the sensory quality of the products and consumer appreciation and 2) if the reformulated products maintained their competitiveness in the market. A discussion of the experimental fallout precedes the conclusions about salt, fat and sugar reductions.

\subsection{Congruency of home and laboratory experiments}

The two experiments involved three measurements of food acceptability for consumers. A traditional pleasantness rating and a willingness to pay procedure was conducted at home, and a controlled ranking task was performed in a laboratory. The employed methods were complementary and provided different results. The pleasantness and sorting tasks are targeted to sensory perception; however, only the latter enables direct comparison. These methods are termed hypothetical since the responses given by the consumer has no impact on him. The influence of the first product on the second product was reduced for the pleasantness rating by a monadic presentation with a two-week interval. The WTP approach is more global because it is not targeted to the sensory dimensions but includes all characteristics of the product and the participant. Against the previous methods, the WTP paradigm is real since the participant response has an impact on him; the procedure is incentive. Furthermore, this method enables to reach a level of sensitivity to evaluate if a consumer is willing to pay an outstanding price for a product offering an outstanding sensory experience.

When no difference between the non-reformulated version and reformulated version was observed for the pleasantness rating in the home experiment (cheese and muffin), the ranking task also revealed no differences between the two versions in the laboratory experiment. In parallel, the price (reservation price) that the participants were willing to pay did not differ. We have demonstrated that the reformulated versions of chorizo and dry sausage were distinctly preferred over the non-reformulated versions of chorizo and dry sausage in the pleasantness ratings. This result was confirmed by a preference for the reformulated versions in the ranking tasks. This distinction between the samples corresponded to the higher maximum price that the subjects are willing to pay in favour of reformulated products. The subjects are willing to pay approximately $12 \%$ more for the reformulated version, which was consistent with the pleasantness and preference results. Therefore, the three measurements are consistent, as indicated by other studies that assessed willingness to pay and pleasantness (Ginon et al., 2009; Lange et al., 2002; Noussair et al., 2004a; Stefani, Romano, \& Cavicchi, 2006) or pleasantness and ranking (Barylko-Pikielna et al., 2004; Léon, Couronne, Marcuz, \& Köster, 1999).

Interestingly, the differences were only perceived based on flavour. The two versions were contained in the same packaging; no label was added to provide any cues regarding reductions or wellbeing. Thus, the results cannot be attributed to packaging, legal information or consumer belief as previous studies had suggested (Ginon et al., 2009; Mialon, Clark, Leppard, \& Cox, 2002; Napolitano et al., 2010; Olesen, Alfnes, Røra, \& Kolstad, 2010). In more than those controlled factors, individual parameters such as sensory experience, salary and social level did not seem to explain the results. Therefore, this paper enabled a cross-validation of the results from the field and laboratory and offers new perspectives for additional home evaluations of pleasantness and willingness to pay.

For cooked sausages, the results were not distinct. Both direct measurements of pleasantness (scale) and preference (ranking) showed that the non-reformulated version was preferred over the reformulated one. In terms of willingness to pay, reservation prices are similar for the two versions and are not higher for the non-reformulated version as expected. This result is considered to derive from a product effect, regardless of the version. The major difference between cooked sausages and the other products of the shopping-bag was the mean pleasantness level: this level was lower for cooked sausage (below 4/10), which reflects a dislike of this product (even in its original version); the other products were appreciated $(>5 / 10)$. As a consequence, if the pleasantness evaluation or preference tests may discriminate the products, it seems that, in our case, the WTP measurement is not appropriate for poorly appreciated products. In this case, the maximum price that the subjects indicated is assumed to be confounded with the minimal price that they are willing to pay for cooked sausages; thus, no differences among the samples were observed. Even if consumers did not really like a product, they would be willing to buy it at a minimal price, which is also the maximum price that they are willing to pay. In sum, the home evaluation of food products (pleasantness and WTP) seems powerful and offers comparable results with a classical laboratory evaluation if a product is not disliked. 
In real situations, consumers buy food and cook it at home in accordance with their own cooking customs. The pleasantness of the course coupled with the price of the product will trigger or not trigger a subsequent purchasing decision that enables a product to join the consumer's food "repertoire" (Zandstra, Weegels, Van Spronsen, \& Klerk, 2004). This study offers a nice perspective because not only the "purchaser" was involved but also the "eater". Then, both product characteristics and cooking customs were considered to evaluate if the product will entered in the consumer food repertoire. In more than the consumer appreciation, the opinion of the other family members may influence the results thus, both measurements probably also reflect in part the family rating with regard to the daily use of purchased products (Lawless \& Heymann, 2010). It also make sense to assess the social impact of food appreciation to evaluate if a product entered the food repertoire of the consumer and of the family. Consequently, the realistic and ecological assessment of appreciation and subsequent purchase decisions is an interesting direction. Field experiments are probably underrepresented in literature as experiments are complex and costly, especially with food samples. However, building home experiments is one of the only way to bypass desirability bias linked with the presence of the experimenter, prevent repeated measurements in lab and offers an overview of the social impact of the consumption at home. In this study, the samples were still commercialized or ready to be; thus an evaluation as close as the consumer seemed better than a study conducted in lab, probably more appropriate for product development. Although experimenters may not feel confident with "less controlled" conditions, the results of this study should encourage home experiments to promote sensory evaluations in real tasting conditions.

\subsection{Impact of reducing fat, salt and sugar on consumer acceptance}

The reformulated samples were derived from different technological reduction strategies that were applied to real food products (Chapeau et al., 2016; Desmond, 2006; Kloss et al., 2015; Mosca et al., 2015; Syarifuddin et al., 2016). The most disappointing results were obtained for cooked sausage: if the participant maintained the maximum price that they were willing to pay, the pleasantness of the product was reduced in the reformulated version compared with the initial non-reformulated version. Accordingly, the ranking task showed that subjects devaluated the " $\mathrm{R}$ " product compared with the initial "NR" version and other brands. This lack of competitiveness is a main issue for subsequent product commercialization and the development of comprehensive formulation processes are needed. At the end of the study, several consumers reported that they did not notice a change in taste between the two versions, which suggests that the reduction strategy was successful. Indeed, the objective for the companies was to reformulate their products without noticeable sensory differences to replace the original version on the market. Preliminary tests with internal panellists of these companies tended to show an absence or weak differences. For cooked sausages a weak higher firmness and mouthfeel roughness has been found for the reformulated version in these preliminary tests but was not expected to impact the appreciation. However, in the present study, participants strongly criticize the texture of one version suggesting that the present reformulation altered other sensory dimensions such as texture. An additional formulation to improve texture may increase product pleasantness.

For the remaining products, reformulation was successful. For cheese and muffins, reformulation maintained consumer appreciation, which was the goal of the TeRiFiQ project, and the products were preferred to the two brands in the competition. From an experimental and economic point of view, the participants are willing to pay the same price, which indicates that the "R" product remains similarly valorised as "NR". If the reduction strategy creates extra cost for a company, these costs will probably not be covered by consumers. The success of the reformulation process was achieved for chorizo and dry sausage. The " $R$ " versions are preferred to the "NR" versions. The rankings indicated that the initial versions were not strong competitors of other brands; however, after reformulation they surpassed the trademark and seriously competed with the store brand. As suggested by the WTP procedure, consumers are willing to pay approximately $12 \%$ more for the preferred product. The objective of WTP is not to predict the price of the reformulated version but only highlight a hierarchy of preference through the reservation price. Indeed, the reservation price may change if other options are available or if the context changes (Combris \& Ruffieux, 2005). Marketing studies are required to predict the price of the future commercialized products. Anyway, the results informed that the consumer is willing to pay a higher price for these versions. Therefore, the potential extra cost of adding new processes for reformulation would be covered by a re-evaluated price if the product gains appreciation.

The strategies developed by industrial partners to reduce fat, salt and sugar content in their commercialized products were successful. They contributed to product harmony with the European Nutrition claims while ensuring product acceptability for consumers. In several cases, reformulation may facilitate improvements in the product competitiveness on the market.

\section{Conclusions}

This study employed different methodologies and combined home and laboratory evaluations of pleasantness and willingness to pay to evaluate the impact of reducing fat, salt and sugar in everyday food products on consumer behaviour. From a methodological point of view, these methods are suitable for assessing product sensory quality and the home experiment enabled the discrimination of two products' versions based on flavour. Regarding the objective, reduction strategies that emerged from the TeRiFiQ project maintained consumer appreciation and acceptance (with the exception of cooked sausage) and occasionally improved the sensory quality of products. Based on this study, some of the reformulated samples sold on the market.

\section{Acknowledgments}

The authors sincerely wish to acknowledge the SMEs: Boadas (Girona, Spain), Millba (Skien, Norway), Orval (Villers-devantOrval, Belgium) and Leiv Vidar (Markedssjef, Norway) for their everyday contribution to the project and for sending products. They also thank all TeRiFiQ partners for their deep involvement in the project, Chloé Letagneaux for her support, Christophe Martin for preliminary fruitful discussions and the ChemoSens Platform (CSGA, Dijon, France) for providing sensory evaluation equipment. This work was supported by the European Union through the Seventh Framework Programme: Combining Technologies to achieve significant binary Reductions in Sodium, Fat and Sugar content in everyday foods whilst optimizing their nutritional Quality (TeRiFiQ Project) FP7 KBBE2011-5-289397. The authors also thank the Regional Council of Burgundy and the FEDER (European Regional Development Fund) for partly financing the structure and equipment used during the project.

\section{Appendix A. Supplementary data}

Supplementary data associated with this article can be found, in the online version, at http://dx.doi.org/10.1016/j.foodqual.2016.10. 009 . 


\section{References}

AFNOR (2012). Analyse sensorielle - Méthodologie - Directives générales pour la réalisation d'épreuves hédoniques effectuées avec des consommateurs dans un espace contrôlé.

Barylko-Pikielna, N., Matuszewska, I., Jeruszka, M., Kozlowska, K., Brzozowska, A., \& Roszkowski, W. (2004). Discriminability and appropriateness of category scaling versus ranking methods to study sensory preferences in elderly. Food Quality and Preference, 15, 167-175.

Becker, G. M., Degroot, M. H., \& Marschak, J. (1964). Measuring utility by a singleresponse sequential method. Behavioral Science, 9, 226-232.

Brauss, M. S., Linforth, R. S. T., Cayeux, I., Harvey, B., \& Taylor, A. J. (1999). Altering the fat content affects flavor release in a model yogurt system. Journal of Agricultural and Food Chemistry, 47, 2055-2059.

Chapeau, A. L., Silva, J. V. C., Schuck, P., Thierry, A., \& Floury, J. (2016). The influence of cheese composition and microstructure on the diffusion of macromolecules: A study using Fluorescence Recovery After Photobleaching (FRAP). Food Chemistry, 192, 660-667.

Combris, P., \& Ruffieux, B. (2005). La révélation expérimentale des préférences des consommateurs. Sciences Sociales, 3-4.

Desmond, E. (2006). Reducing salt: A challenge for the meat industry. Meat Science, 74(1), 188-196.

Drewnowski, A., \& Greenwood, M. R. (1983). Cream and sugar: human preferences for high-fat foods. Physiology \& Behavior, 30, 629-633.

Drewnowski, A., Nordensten, K., \& Dwyer, J. (1998). Replacing sugar and fat in cookies: Impact on product quality and preference. Food Quality and Preference, 9, 13-20.

EFSA (2008). The setting of nutrient profiles for foods bearing nutrition and health claims pursuant to Article 4 of the Regulation (EC) No 1924/2006. The EFSA Journal, 644, 1-44.

Emorine, M., Septier, C., Thomas-Danguin, T., \& Salles, C. (2013). Heterogeneous salt distribution in hot snacks enhances saltiness without loss of acceptability. Food Research International, 51, 641-647.

European Commission (2007). A strategy for Europe on nutrition, overweight and obesity related health issues. 52007DC0279.

European Parliament (2006). Regulation (EC) No 1924/2006 of the European Parliament and of the Council of 20 december 2006 on nutrition and health claims made on foods.

Ginon, E., Lohéac, Y., Martin, C., Combris, P., \& Issanchou, S. (2009). Effect of fibre information on consumer willingness to pay for French baguettes. Food Quality and Preference, 20, 343-352.

Ginon, E., Combris, P., Loheac, Y., Enderli, G., \& Issanchou, S. (2014). What do we learn from comparing hedonic scores and willingness-to-pay data? Food Quality and Preference, 33, 54-63.

Goh, F. X. W., Itohiya, Y., Shimojo, R., Sato, T., Hasegawa, K., \& Leong, L. P. (2011) Using naturally brewed soy sauce to reduce salt in selected foods. Journal of Sensory Studies, 26, 429-435.

Katsiari, M. C., Voutsinas, L. P., Alichanidis, E., \& Roussis, I. G. (1997). Reduction of sodium content in Feta cheese by partial substitution of $\mathrm{NaCl}$ by $\mathrm{KCl}$. International Dairy Journal, 7, 465-472.

Kloss, L., Meyer, J. D., Graeve, L., \& Vetter, W. (2015). Sodium intake and its reduction by food reformulation in the European Union - A review. Nutrition and Food Science Journal, 1, 9-19.

Lange, C., Martin, C., Chabanet, C., Combris, P., \& Issanchou, S. (2002). Impact of the information provided to consumers on their willingness to pay for Champagne: Comparison with hedonic scores. Food Quality and Preference, 13, 597-608.

Lawless, H. T., \& Heymann, H. (2010). Consumer field tests and questionnaire design. In D. R. Heldman (Ed.), Sensory evaluation of food (2nd ed., pp. 349-378). New York, NY: Springer New York.

Lawrence, G., Salles, C., Septier, C., Busch, J., \& Thomas-Danguin, T. (2009). Odourtaste interactions: A way to enhance saltiness in low-salt content solutions. Food Quality and Preference, 20, 241-248.
Léon, F., Couronne, T., Marcuz, M., \& Köster, E. (1999). Measuring food liking in children: A comparison of non verbal methods. Food Quality and Preference, 10, 93-100.

Lobato-Calleros, C., Sosa-Pérez, A., Rodríguez-Tafoya, J., Sandoval-Castilla, O., PérezAlonso, C., \& Vernon-Carter, E. J. (2008). Structural and textural characteristics of reduced-fat cheese-like products made from $\mathrm{W} 1 / \mathrm{O} / \mathrm{W} 2$ emulsions and skim milk. LWT - Food Science and Technology, 41, 1847-1856.

Mialon, V. S., Clark, M. R., Leppard, P. I., \& Cox, D. N. (2002). The effect of dietary fibre information on consumer responses to breads and "English" muffins: A crosscultural study. Food Quality and Preference, 13, 1-12.

Mosca, A. C., Andriot, I., Guichard, E., \& Salles, C. (2015). Binding of $\mathrm{Na}^{+}$ions to proteins: Effect on taste perception. Food Hydrocolloids, 51, 33-40.

Napolitano, F., Braghieri, A., Piasentier, E., Favotto, S., Naspetti, S., \& Zanoli, R. (2010). Effect of information about organic production on beef liking and consumer willingness to pay. Food Quality and Preference, 21, 207-212.

Noussair, C., Robin, S., \& Ruffieux, B. (2004a). A comparison of hedonic rating and demand-revealing auctions. Food Quality and Preference, 15, 393-402.

Noussair, C., Robin, S., \& Ruffieux, B. (2004b). Revealing consumers' willingness-topay: A comparison of the BDM mechanism and the Vickrey auction. Journal of Economic Psychology, 25, 725-741.

Olesen, I., Alfnes, F., Røra, M. B., \& Kolstad, K. (2010). Eliciting consumers willingness to pay for organic and welfare-labelled salmon in a nonhypothetical choice experiment. Livestock Science, 127, 218-226.

Oppermann, A. K. L., Renssen, M., Schuch, A., Stieger, M., \& Scholten, E. (2015). Effect of gelation of inner dispersed phase on stability of (w1/o/w2) multiple emulsions. Food Hydrocolloids, 48, 17-26.

Perez-Moral, N., Watt, S., \& Wilde, P. (2014). Comparative study of the stability of multiple emulsions containing a gelled or aqueous internal phase. Food Hydrocolloids, 42, 215-222.

Pinheiro, J., Bates, D., DebRoy, S., Sarkar, D., \& R Core Team (2015). nlme: Linear and nonlinear mixed effects models. Retrieved from http://cran.r-project. org/package=nlme.

R Core Team (2015). R: A language and environment for statistical computing. Vienna, Austria: R Foundation for Statistical Computing.

Safa, H., Gatellier, P., Lebert, A., Picgirard, L., \& Mirade, P.-S. (2015). Effect of combined salt and animal fat reductions on physicochemical and biochemical changes during the manufacture of dry-fermented sausages. Food and Bioprocess Technology, 8, 2109-2122.

Schifferstein, H. N., Kole, A. P., \& Mojet, J. (1999). Asymmetry in the disconfirmation of expectations for natural yogurt. Appetite, 32, 307-329.

Siret, F., \& Issanchou, S. (2000). Traditional process: influence on sensory properties and on consumers' expectation and liking Application to "pâté de campagne". Food Quality and Preference, 11, 217-228.

SSHA (1998). Évaluation sensorielle: manuel méthodologique (2nd ed.). Tec \& Doc Lavoisier. 169-171, 175-177.

Stefani, G., Romano, D., \& Cavicchi, A. (2006). Consumer expectations, liking and willingness to pay for specialty foods: Do sensory characteristics tell the whole story? Food Quality and Preference, 17, 53-62.

Syarifuddin, A., Septier, C., Salles, C., \& Thomas-Danguin, T. (2016). Reducing salt and fat while maintaining taste: An approach on a model food system. Food Quality and Preference, 48, 59-69.

Vickrey, W. (1961). Counterspeculation, auctions, and competitive Sealed tenders. The Journal of Finance, 16, 8-37.

Zandstra, E., Weegels, M., Van Spronsen, A., \& Klerk, M. (2004). Scoring or boring? Predicting boredom through repeated in-home consumption. Food Quality and Preference, 15, 549-557.

Zoulias, E., Oreopoulou, V., \& Kounalaki, E. (2002). Effect of fat and sugar replacement on cookie properties. Journal of the Science of Food and Agriculture, 82, 1637-1644. 